\title{
STUDIES OF THE BASAL WORK AND OUTPUT OF THE HEART IN CLINICAL CONDITIONS
}

\author{
BY ISAAC STARR, JR., LEON H. COLLINS, JR., AND \\ FRANCIS CLARK WOOD \\ (From the Medical Division of the Hospital of the University of Pennsylvania and the \\ Laboratory of Pharmacology, University of Pennsylvania, Philadelphia)
}

(Received for publication July 27,1932 )

Any method of determining the volume of the cardiac output in man which requires intelligent, alert and active cooperation by the subject can scarcely be regarded as suited to the study of this most important aspect of cardiac function in the clinic. Errors are sure to arise from ignorance, lack of training, excitement, apprehension, etc., of such magnitude as to render results worthless. When the ethyl iodide method of Henderson and Haggard (1) was devised, in which the sole requirement of the subject is that he breathe through a mouthpiece, it appeared that a long step had been taken toward the attainment of quantitative information concerning the heart's output under the various circumstances of disease. Impressed by these possibilities Starr and Gamble, at the suggestion of Professor A. N. Richards and with generous assistance from Professor Henderson, learned to use the method and began the study of normal subjects in order to accumulate the experience and the data requisite for its profitable application to patients. Unfortunately discrepancies were soon encountered between their experiences and those which Henderson and Haggard had published.

It was soon evident that, by means of the analytical method of Henderson and Haggard, known concentrations of ethyl iodide could not be estimated with satisfactory accuracy. It was therefore necessary to devise new methods which met this requirement (2). Employing these methods Starr and Gamble were unable to verify certain of the conceptions on which the original method was based, namely the absence of ethyl iodide from blood returning to the lungs, and the size of the distribution coefficient for ethyl iodide between air and blood (3). They were therefore confronted with the question of abandoning the project altogether or of so altering the plan of the method that it should yield results in which they could have confidence. The latter alternative was chosen, the distribution coefficient was redetermined and the method was redesigned so that the relatively large amount of ethyl iodide in venous blood could be estimated at each determination of cardiac output. By means of this new method it was found possible to make satisfactory estimations of the flow of blood perfused through the lungs of dogs at a known rate 
(4). Also numerous experiments on man gave evidence that it was proper to employ the method for the determination of cardiac output in resting subjects. These modifications of the original ethyl iodide method and of the conceptions underlying it have recently been approved by Professor Henderson (5).

With these improvements duplicate determinations of the cardiac output of trained subjects yielded results which showed an average difference of only 6 per cent (6). On one subject under conditions of basal metabolism fifteen estimations have been made on seven days scattered over a period of four years. There is no significant difference among these results, the most divergent being less than 9 per cent, the average deviation being 4 per cent from the mean of the series. Although all subjects do not yield results as consistent as these, it seems proper to suppose that the cardiac output is relatively constant when conditions are suitable and that there exists a definite basal level of cardiac output analogous to the basal metabolic rate.

The next task was to discover how best to secure a basal cardiac output in patients and to find the factors which, by increasing cardiac output, would prevent the attainment of this condition. It was found that a longer rest period was necessary than that ordinarily employed before a determination of basal metabolic rate. Cold, the taking of food, and excitement were found to increase cardiac output, and so must be avoided if the basal cardiac output is to be determined (6).

During this investigation other methods of measuring cardiac output were being developed and improved in other laboratories. At present a number of methods give an average result on normal young adult males which is quite similar to that obtained by our method. The diversity of the means employed in these methods, e.g. acetylene and a modified Krogh and Lindhard technique by Grollman (7), cardiac puncture and the Fick principle by Lauter (8), x-ray photography by Meek and Eyster (9), gives us confidence in the approximate correctness of our results. Though some methods have certain advantages over our procedure, all but that of Meek and Eyster, which has certain disadvantages, either disturb the subject by puncturing the skin or by requiring his cooperation, and so appear to us less suitable for use on untrained patients than the procedure we employ.

Therefore it appeared that the time had come to carry out the original intention of studying cardiac output in the clinic and to attempt to answer the question whether the method of Starr and Gamble was sufficiently accurate to throw light on the diagnosis and treatment of cardiac disease and on other questions of cardiac physiology. Accordingly, duplicate determinations of basal cardiac output were made in various types of patients. About twenty-five cases had been tested before the data disclosed that in estimating the condition of the heart, the basal cardiac 
output was of less significance than the cardiac work. The results also indicated that the basal work of the heart was a function of its size, a finding which suggested that Starling's Law of the Heart was applicable to clinical conditions. Therefore, we decided to attempt to estimate the magnitude of the heart's work in the common clinical conditions in which our method could be properly utilized.

We have now assembled duplicate determinations on 50 persons who were lying at rest fifteen or more hours after the last meal. Seeking for diverse conditions we have studied cases whose pulse rate ranged from 46 to 142 , the blood pressure from $94 / 50$ to $210 / 130$, the cardiac output from 1.3 to 7.5 liters per minute, and the cardiac silhouette area from 69 to 200 $\mathrm{cm}^{2}$. Among these cases are apparently normal persons, patients threatened with congestive failure, and patients with some circulatory abnormality but not threatened with failure, i.e. hypertension, hyperthyroidism, angina pectoris, anemia, compensated valvular heart disease and functional heart disease. In cases not threatened with congestive failure the relationship between the left ventricular work per beat and the area of the cardiac silhouette or the volume of the heart is approximately linear, and the deviation of the great majority of values from the best line is within the limits of error. Values obtained from patients threatened with failure are significantly different from these. They demonstrate inefficient hearts, doing but little work in proportion to their size. This affords confirmation of the classic conception of cardiac failure and may afford an additional means of diagnosis of this condition.

\section{METHODS}

The details of our method have been described (4). The subjects during each respiratory cycle inhale a concentration of ethyl iodide which causes no discomfort, being indeed not much more than perceptible. After about 20 minutes of such inhalation, samples are taken of inspired, expired, alveolar and rebreathed air. A second group of samples is taken about 10 minutes later. The difference of ethyl iodide content in inspired and expired air multiplied by the volume of respiration gives the amount of this gas absorbed from the lungs. The difference between the contents of alveolar and rebreathed air, in tension equilibrium with arterial and mixed venous bloods respectively, multiplied by the distribution coefficient of ethyl iodide between air and blood, gives the amount of the gas carried away by each unit of blood. The quotient of these two items gives the amount of blood which flows through the lungs, i.e. the cardiac output. In calculating the results recorded in Table II we have omitted one of the small corrections previously employed, that for the change of ethyl iodide in rebreathed air with time. This correction has proved to be insignificant in determinations of this kind. 
In the great majority of cases we employed the average distribution coefficient of ethyl iodide between air and blood, 6.1, which when corrected to the usual room temperature and vapor tension became $5.6(4)$. In cases of anemia and of diabetes this coefficient was determined and the result utilized. The volume of respiration during the period in which the samples were taken, usually $21 / 2$ minutes, was employed in the calculation. Blood pressures were determined by the auscultatory method, and pulse rates were counted during this same period.

The metabolism was determined by slowly drawing samples of expired air from the mixing bottle during the period in which the cardiac output samples were taken. A second estimation of metabolism coincided with the second cardiac output determination. Thus the same volume of respiration was used for calculating both metabolism and cardiac output, and the samples used in both determinations were taken as nearly simultaneously as technical considerations would permit. The analyses were done in duplicate in the large majority of instances. The respiratory quotient employed was that determined except in the few cases in which it was altered by obvious hyperventilation, when 0.82 was assumed. The standards used were those of DuBois.

The size of the heart was determined by orthodiagraph with the patient standing. The anteroposterior silhouette was drawn at the end of a normal inspiration and its area computed by a planimeter. Many of these determinations were done immediately after that of the cardiac output and metabolism. All those on patients were done within a few days. However in seven normal persons (numbers 43 to 49), whose basal cardiac output had been determined in a previous investigation (6), the orthodiagrams were made about a year later.

The analyses pertaining to cardiac output were almost entirely performed by Starr, those concerned with metabolism by Collins and the majority of orthodiagrams were made by Wood. We are indebted to Dr. Alexander Margolies for the remainder of the orthodiagrams. The person determining the heart size was never aware of the other findings.

On the avoidance, detection, or evaluation of certain errors

We have not omitted any result from Table IV or Figure 1. However, certain considerations make some of doubtful validity:

(1) Failure to attain the basal condition. Aside from conditions in which the metabolism was elevated by disease, thyrotoxicosis and some cases of threatened congestive failure, only two of our cases (numbers 9 and 11) failed to attain the basal condition in at least one of the two estimations. Five cases attained it in only one of the duplicates, but when the average of the two is within normal limits we do not regard the deviation of one as significant. Therefore we have evidence that most of 
our subjects were under no emotional strain when their cardiac output was estimated and we attribute this to the fact that no cooperation was required. But we believe that under certain circumstances it is possible to have a basal metabolic rate without a basal cardiac output. For this reason our preliminary rest period was always longer than that ordinarily used to secure a basal metabolic rate.

(2) Uncertainty concerning tension equilibrium between alveolar air and arterial blood. This equilibrium, which has been demonstrated for ethyl iodide when the lungs are normal (4), cannot be assumed to exist when the lungs are abnormal. No patient whose lungs were manifestly abnormal has been included in our series. The cases of "threatened congestive failure" were persons who had been decompensated but had regained compensation under treatment, and in whom abnormal pulmonary physical signs could no longer be detected. None of them showed any cyanosis. In the case which appeared to us closest to actual decompensation (number 26) the oxygen saturation of the arterial blood was 89 per cent, just outside normal limits. We do not believe that the pathologic change in the lungs would cause significant error in this case, for the more soluble ethyl iodide may be expected to pass through the lungs with more facility than oxygen. Cases having emphysema were avoided.

(3) Hyperventilation. The fact that certain patients overventilate and blow off their $\mathrm{CO}_{2}$ when breathing through apparatus is well known. We have encountered this type. One patient (number 1 and 2) showed this phenomenon only on certain occasions. This gave us the opportunity to determine its effect on the cardiac output and work. The results (Table IV) show that when respiration was elevated, basal cardiac output and work were usually exceeded. When the respiration was normal the cardiac output and work were at a minimum and reasonably consistent. Therefore hyperventilation is a valid cause for discarding a result. The results charted for this patient have been selected from those in which the respiration was not unduly elevated. When other patients hyperventilated (cf. numbers 12 and 30 ) the results have been charted but will be commented on below.

It is noteworthy that the alveolar $\mathrm{CO}_{2}$ of our untrained subjects at the end of the breathing period averaged only 4.73 per cent as against 5.34 per cent for our trained subjects. This reduction was plainly due to overbreathing in a few of our subjects and may well have been influenced by acidosis in some others. That untrained subjects, breathing through metabolism apparatus, usually blow off $\mathrm{CO}_{2}$ has been demonstrated by Heckscher (10) and we believe that this factor has entered into our results also. The low figures are not to be attributed to any error in our method of obtaining alveolar air, for Haldane-Priestley samples taken on a number of cases contained amounts of $\mathrm{CO}_{2}$ of about the same magnitude. 
(4) Errors inherent in the estimation of cardiac work. The work of the heart may be calculated from the familiar formula (11)

$$
W=Q R+\frac{w V^{2}}{2 g},
$$

where $W=$ work done per minute or per beat; $Q=$ volume of blood expelled per minute or per beat; $R=$ arterial resistance $=$ mean arterial pressure in $\mathrm{mm}$. $\mathrm{Hg} \times 13.6 ; V=$ velocity of blood at aorta; $w=$ weight of blood; $g=$ acceleration due to gravity.

The expression $w V^{2} / 2 g$ represents the work done in imparting velocity to the blood. To estimate it, one would have to make certain assumptions. Assuming that the aortic diameter is $2.8 \mathrm{~cm}$., that systole is proportional to the square root of the cardiac cycle (12) and that the expulsion period equals systole minus 0.06 second we have calculated the velocity factor for the four cases having the largest cardiac outputs and highest pulse rates. In no case did this factor represent more than 2 per cent of the calculated cardiac work. As this factor would certainly be smaller in the other determinations we have omitted it from our calculations altogether.

The error inherent in our cardiac output determinations has been discussed $^{1}$ (6). Unfortunately, there is no means of accurately evaluat-

${ }^{1}$ Lindhard (33) makes the statement that the maximal error inherent in the estimation of ethyl iodide in $500 \mathrm{cc}$. of air by our method is $0.3 \mathrm{mgm}$. This is erroneous; the context suggests that it is a misprint for $0.03 \mathrm{mgm}$., the average error in the analysis of a single sample. But the following statement that this error induces an error of 6 to 7 per cent in the result of each of the four samples of a cardiac output estimation is likewise incorrect. This percentage is applicable to the smallest of the factors utilized to calculate cardiac output (4). In this same article the description of our technique of obtaining air in equilibrium with venous blood is also incorrect. Our subjects rebreathe for 30 seconds in and out of a bronze bag and not for 2 minutes in a Douglas bag as there stated.

In this investigation the smallest factor appearing in the calculation of cardiac output (the alveolar ethyl iodide concentration minus the rebreathed concentration) was usually much larger than in previous experiments and the influence of the error inherent in the analysis on the calculated cardiac output is correspondingly smaller.

It must be remembered that, when the accuracy of our analytical method was evaluated by the estimation of known amounts of ethyl iodide, the apparent error was affected by that inherent in the weighing and handling of such small quantities. Also in the calculation of cardiac output the values obtained by analysis are subtracted one from another, and they appear in both the numerator and denominator of the equation. Therefore any errors which changed these values by a like amount, as those caused by constant under- or overtitration, would not affect the calculated cardiac output. Similarly, any error which affected all four values proportionately would also cancel out. These reasons afford an explanation of the fact that the duplicate estimations of cardiac output on trained subjects agree better than one might expect from our accuracy in estimating weighed amounts of ethyl iodide. 
ing the absolute error. The average deviation of the forty-seven duplicates from their mean is 6 per cent. The standard deviation is 7.3 per cent. Therefore differences of 20 per cent are likely to be significant. The differences between duplicate estimations in trained and untrained subjects are given in Table $I$ and average about 6 per cent and 11 per cent

TABLE I

Average difference between results of duplicate determinations in per cent of their mean

\begin{tabular}{c|c|c|c|c}
\hline \hline & $\begin{array}{c}\text { Respiration. } \\
2 \frac{3}{2} \text { minute period }\end{array}$ & $\begin{array}{c}\text { Metabolism. } \\
\text { 2t minute period }\end{array}$ & $\begin{array}{c}\text { Cardiac output } \\
\text { per minute }\end{array}$ & $\begin{array}{c}\text { Cardiac work } \\
\text { per beat }\end{array}$ \\
\hline per cent & per cent & per cent & per cent \\
$\begin{array}{c}\text { In } 9 \text { trained subjects } \\
\text { (normals) } \ldots \ldots \ldots \ldots \ldots\end{array}$ & 2.8 & 6.5 & 6.5 \\
$\begin{array}{c}\text { In } 44 \text { untrained subjects } \\
\text { (hospital patients) } \ldots . . .\end{array}$ & 7.2 & 9.9 & 11.4 & 10.8 \\
\hline
\end{tabular}

of the corresponding means. These differences are of about the same magnitude as those found in measuring metabolism ${ }^{2}$ and not much larger than those observed in measuring respiratory minute volume. In ten subjects the change in respiration will almost completely account for the difference between the duplicate cardiac outputs. Trained subjects are more consistent than untrained ones in every item.

We regard automatic sampling of alveolar air as the chief hazard in our method. The respiratory tracing permits the detection of the shallow or irregular types of breathing which would invalidate this method. We have encountered very few of these and we have made no eliminations on this score. Untrained subjects usually breathe fairly deeply through apparatus. Also in most of our patients the arteriovenous ethyl iodide difference is large. Therefore small errors due to faulty automatic sampling would make but little difference in the calculated cardiac output.

In calculating arterial resistance we have made the usual assumption that the mean of systolic and diastolic pressures equals the integral of the pressure curve. Starling (13) evaluated the maximum error of this assumption at 10 per cent; Frank (14) also regarded the error introduced as 10 per cent, but exceptionally it might be much higher (15). In our series it would probably be largest in the cases of hyperthyroidism (numbers 11, 21, 22, 23, and 28) and in the one case with aortic regurgitation (number 24). The one case of auricular fibrillation in the series was under the influence of digitalis and there was no difficulty in estimating

${ }^{2}$ It is to be remembered that the metabolism determinations were for short periods, usually $21 / 2$ minutes, to make them coincide exactly with the cardiac output determinations. The deviation of the duplicates is therefore considerably larger than is usual in determinations made over longer periods of time. 
blood pressure. We believe that the error would be large only in unusual conditions and so, considering our series as a whole, we have estimated the error involved at 10 per cent. We are by no means certain that the usual method of estimating diastolic pressure gives the correct result, but this error would be largely systematic, and we lack the data necessary to assign a value to it.

(5) The error in estimating cardiac size. To determine the personal error in drawing the silhouette ten patients were studied by Dr. Wood and Dr. Margolies independently. The average difference between the silhouette areas of each patient was 5.9 per cent of the smaller value; the maximum difference was 13 per cent. The largest absolute differences were in patients with large hearts, the shadow of the lower border being lost in the diaphragmatic shadow. The largest percentile differences were in patients with very small hearts.

The error in estimating cardiac volume from the silhouette was studied by Bardeen. By applying a formula, heart volume $=0.53 \mathrm{~A}^{3 / 2}$, where $A$ was the area of the silhouette in the anteroposterior position in $\mathrm{cm} .{ }^{2}$, he estimated the heart volume of 63 cadavers. In 45 cases the error was less than 10 per cent. The error in the living should be less, for movement aids greatly in the identification of the cardiac border. Bardeen believed it to be less than $\mathbf{5}$ per cent in the majority of instances (16).

Certain factors might make the cardiac silhouette area bear an inconstant relation to the volume of the heart. In some hearts the anteroposterior diameter bears an unusual relationship to the transverse diameter. Also in large hearts the chambers do not always enlarge proportionately. Especially in mitral stenosis the percentage of cardiac area contributed by the left ventricle may be smaller than in normal hearts or in hearts whose enlargement is due to other lesions.

Therefore it seemed to us that our error was larger than that suggested by Bardeen. We have allowed \pm 10 per cent for this error, but under exceptional circumstances it might be much larger than this.

Our data permit us to estimate the work of the left ventricle. There is evidence that the work of the right ventricle bears a constant relationship to this (17). We prefer to avoid the assumptions necessary to calculate the work of the whole heart. In our discussion only the left ventricular work will be considered.

In discussing the relations of the volume of the heart, demonstrated to be approximately equal to 0.53 area $^{3 / 2}$ by Bardeen, we have omitted the constant $(0.53)$ for the sake of simplicity. 
On the statistical methods and terminology used in the analysis of the data ${ }^{3}$

For brevity in the description of our data, we have made use of the ordinary statistical terminology. As these terms are not yet common in clinical literature it is proper to indicate their meaning. The mean needs no explanation. The standard deviation is a measure of the deviation of the individual values from the mean of the group. In most of our charts the points appear to have arranged themselves about a straight line. The line which fits the points best can be calculated and is called the best line or the regression line. There are two such lines for most groups of values but only one of them, the regression of cardiac work on heart size, deserves consideration in our discussion. The standard deviation about a regression line is a measure of the deviation of the points from this line. The correlation coefficient is likewise a measure of this deviation. A coefficient of plus or minus 1.00 indicates perfect correlation, all the points being on a line. A coefficient of 0 indicates no correlation, the points being scattered without regard to any line.

A summary of the statistical analysis is given in Tables II and III, and statistical methods have been employed in placing lines on certain of the figures. The solid line $A B$ represents the best line, the regression of heart work on heart size, for the control group. On either side of $A B$, at a distance equal to twice the standard deviation about the regression line for the control group, the broken lines $C D$ and $E F$ have been placed. These lines should enclose approximately 95 per cent of all similar "control" cases. Accordingly only 5 per cent of such cases would lie outside the enclosed area, and therefore the probability is about 97.5 in 100 that any result falling to the right of this area was secured in a case which was abnormal in respect to the relationship illustrated by the chart.

It is of some interest to compare the limits of the control group based on its statistical distribution with our estimates of the errors involved in our determinations as discussed before. Allowing 20 per cent, 10 per cent and 10 per cent for the errors in the estimations of cardiac output, mean blood pressure and heart size respectively, we have constructed on Figure 1 the lines $G H$ and $K L$ which would include in the area between them all the points whose deviation from the best line $A B$ could be explained by the errors which we believe to be inherent in these estimations. Almost all of the results obtained on the control group fall within this area; those obtained on the cardiac group are all outside it. However, since we can never hope to obtain an accurate estimate of the size of our absolute errors, the statistical methods afford the better means of determining significant deviations from the normal.

${ }^{3}$ We are indebted to Dr. W. C. Stadie for instruction and assistance in the statistical analysis of the data. 


\section{RESULTS}

The results are given in detail in Table IV, which has been placed at the end of this paper. For the purpose of study and analysis the cases have been divided into several groups.

Group I consists of six cases of cardiac disease, who, though now compensated, at one time had congestive failure. Therefore there can be no doubt that they had serious myocardial disease. They are shown on the charts (Figures 1, 2, 3 and 5) as squares and in Table IV, numbers 24 to 29.

Group II is composed of seventeen cases of hypertension whose cardiac condition appeared to be satisfactory (Figures 1 to 5 , Table IV, numbers 1 to 17$)$.

Group III is a mixed group of 22 cases including normal persons, cases of hyperthyroidism, anemia, functional heart disease, well compensated valvular heart disease, and two cases of angina pectoris (Figures $1,2,3,5$ and Table IV, numbers $19,21,30$ to 49 ).

The control group consists of Groups II and III considered together, and stands in contrast to the cardiac group. The cases in Groups II and III are united by the fact that none of them has ever had congestive failure nor did any appear to be immediately threatened with it. The union of these two groups represents an attempt to gather together cases with normal myocardia, subjected to different types of strain. The cases of angina pectoris are included in it because it was found that they did not differ significantly from the rest of the group. All these cases have been placed in the figures as circles.

The propriety of combining Groups II and III into a single group has other support. In the relationship in which we are most interested, that of cardiac work and heart volume, the statistical criteria indicate that there is a well marked degree of correlation in both groups and that the regression lines are not significantly different for the two groups. Therefore, it is proper to combine them and this gives both an increased number of cases and a greatly increased range of cardiac size. But in numerous other relationships as in Table III, item 2, the two groups are significantly different. Therefore, in the discussion of these relationships they will be considered separately and the data given in Tables II and III show both the relationships of the combined group and that of its two component groups.

Four borderline cases could not be properly included in the above groups. Two cases of severe hyperthyroidism, numbers 22 and 23 , showed symptoms suggestive of threatened myocardial failure but had never actually become decompensated. Number 20 was a case of severe gastric hemorrhage who was in shock when tested. In Case 50, one pair of determinations was made during an attack of paroxysmal tachycardia. The results on these four cases have been placed on the figures, the first three as circles, the last as a square. But they have not been included in the statistical analysis.

In three cases estimations were unsatisfactory because basal conditions were not attained. Case 32 was a young woman who had the symptoms, appearance 
and pulse rate which suggested hyperthyroidism, but her basal metabolic rate had never been abnormal. Her excitement during the determinations manifested itself by a larger increase in cardiac output than in metabolic rate. Case 12 hyperventilated, the alveolar $\mathrm{CO}_{2}$ falling to 2 per cent. Just after the first estimation on Case 9, accidental micturition excited the patient and the great increase in cardiac work which resulted illustrates the strain which emotion may put on the heart of a patient with hypertension. These results have been omitted from the statistical analysis. They have been charted in Figure 1, but have been omitted from the other figures.

The chief interest in our results lies in the consideration of the groups of cases. We selected these cases from diverse conditions in the belief that any relationship which held for all might be expected to be fundamental. That such a relationship exists for the control group is illustrated in the figures and they will now be discussed in detail.

Figure 1 shows the relationship between the left ventricular work per beat and the area of the cardiac silhouette. Each of the duplicate determinations has been charted and no results have been omitted. It will be seen at once that the great majority of circles representing the control group are arranged about the line $A B$ while the squares representing the cardiac group are far distant. The lines $C D$ and $E F$ define limits of the control group selected on the basis of statistical analysis. The lines $G H$ and $K L$ limit the deviations from $A B$ which could be accounted for by our estimates, by other than statistical criteria, of the errors inherent in our methods. Both these sets of lines enclose most of the circles in the area between them. Indeed the position of most of those outlying on the upper side may be explained by failure to attain the basal condition. Those outlying on the lower side represent cases whose hearts may not be normal. The squares lie well outside these areas. The deviation of the values of the control group from the line $A B$ may be explained as due to the errors to which our procedure is subject, but the position of the values of the cardiac group cannot be so explained. Therefore our results show that there is a definite relationship between the heart's area and the basal cardiac work per beat in the cases not threatened with failure, whereas in cardiac cases this relationship does not hold.

Figure 2 differs from Figure 1 in that cardiac volume has been substituted for cardiac area on the horizontal coordinate. The values shown are averages of the duplicate determinations, and the unsatisfactory results on the three cases mentioned above have been omitted. The results again show the relationship between heart size and basal cardiac work per beat which exists in the control group, but does not hold for the cardiac group.

Figure 3 differs from the preceding figure in that left ventricular work per minute has been substituted for work per beat on the vertical coordinate. Though the relationship of heart size and work still holds for the 
control group it is not so close and there is more overlapping with the cardiac group than in Figures 1 and 2.

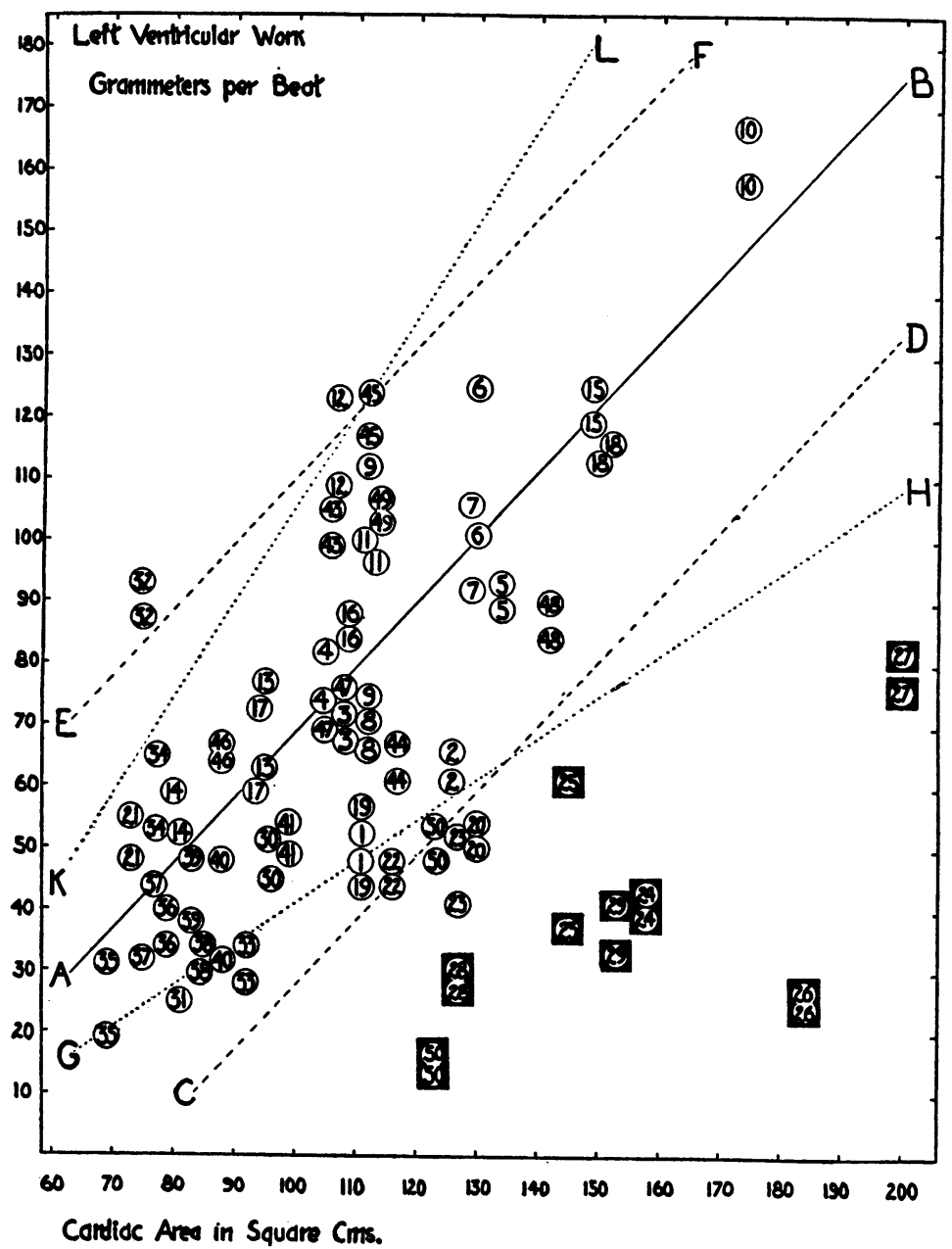

Fig. 1. Left Ventricular Work Per Beat and the Area of the Cardiac SilhouetTe

Each of the duplicate determinations has been charted. The numbers refer to the cases as recorded in Table IV. The values for the cardiac group (Group I), and the case of paroxysmal tachycardia in an attack, are recorded as squares; the remainder as circles. No cases have been omitted.

The line $A B$ represents the best line for the control group of cases, the regression of the work on the area. Lines $C D$ and $E F$ have been placed at a distance of twice the standard deviation from $A B$, and define the approximate limits of this group as determined by statistical methods. On the other hand, the lines $G H$ and $K L$ limit the deviations from $A B$ which could be accounted for by jour estimates, by other than statistical criteria, of the errors inherent in our methods. 
Figure 4 has the same coordinates as Figure 2 but only the cases of hypertension have been charted. This group is of especial interest because of the great differences of heart size which occur within it. In spite of these differences the relationship between heart volume and heart work per beat is very striking and the figure has been given to illustrate this.

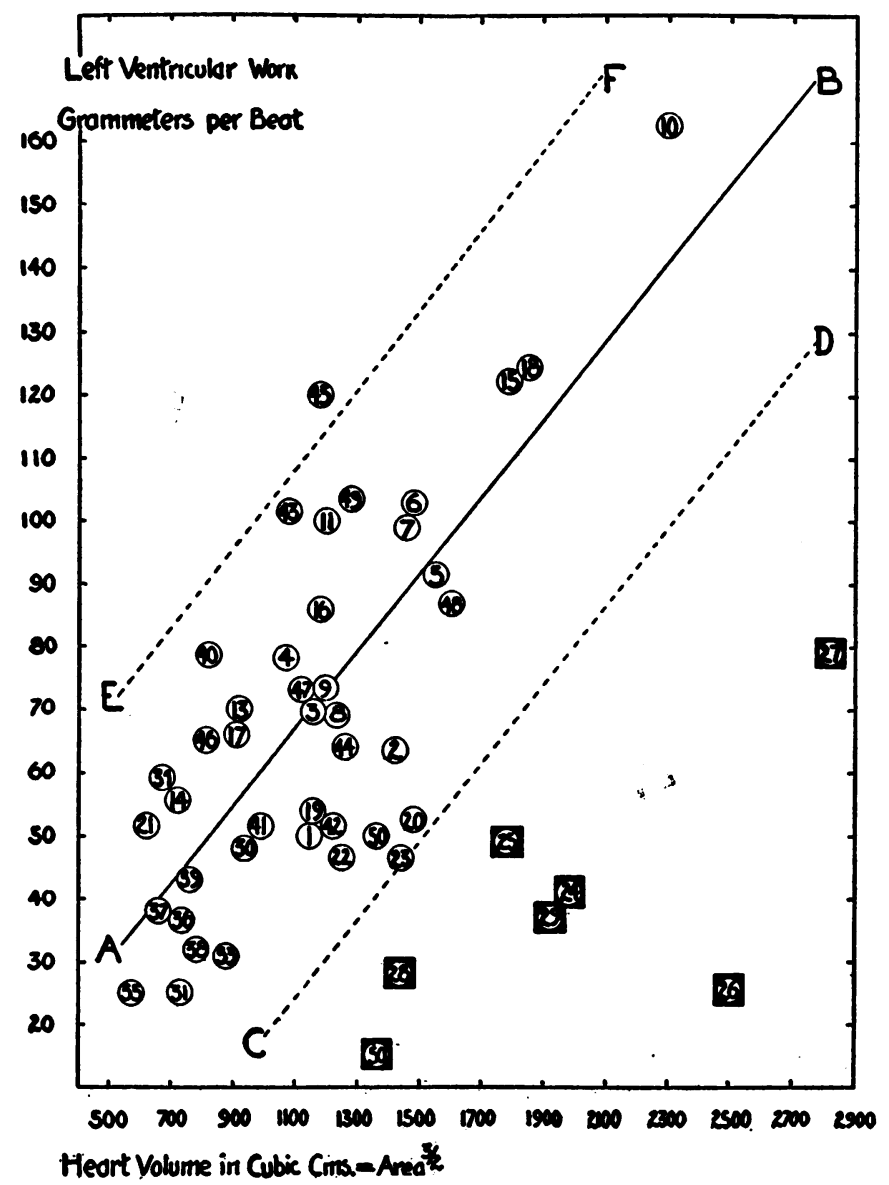

Fig. 2. Left Ventricular Work per Beat and Cardiac Volume

The values charted are the average of duplicate estimations. The unsatisfactory results on three cases have been omitted. Lines and symbols as in Fig. 1.

Figure 5 has been given for the sake of contrast with the other figures. It has been customary to report the results obtained by cardiac output methods in terms of output per minute per square meter of body surface. Figure 5 shows the almost complete lack of relationship between basal cardiac output per minute and body surface in our patients. This will be discussed later. 
A summary of the statistical analysis is given in Tables II and III. The former shows the means of the more important observations together with the standard deviation of the values from their mean. Table III

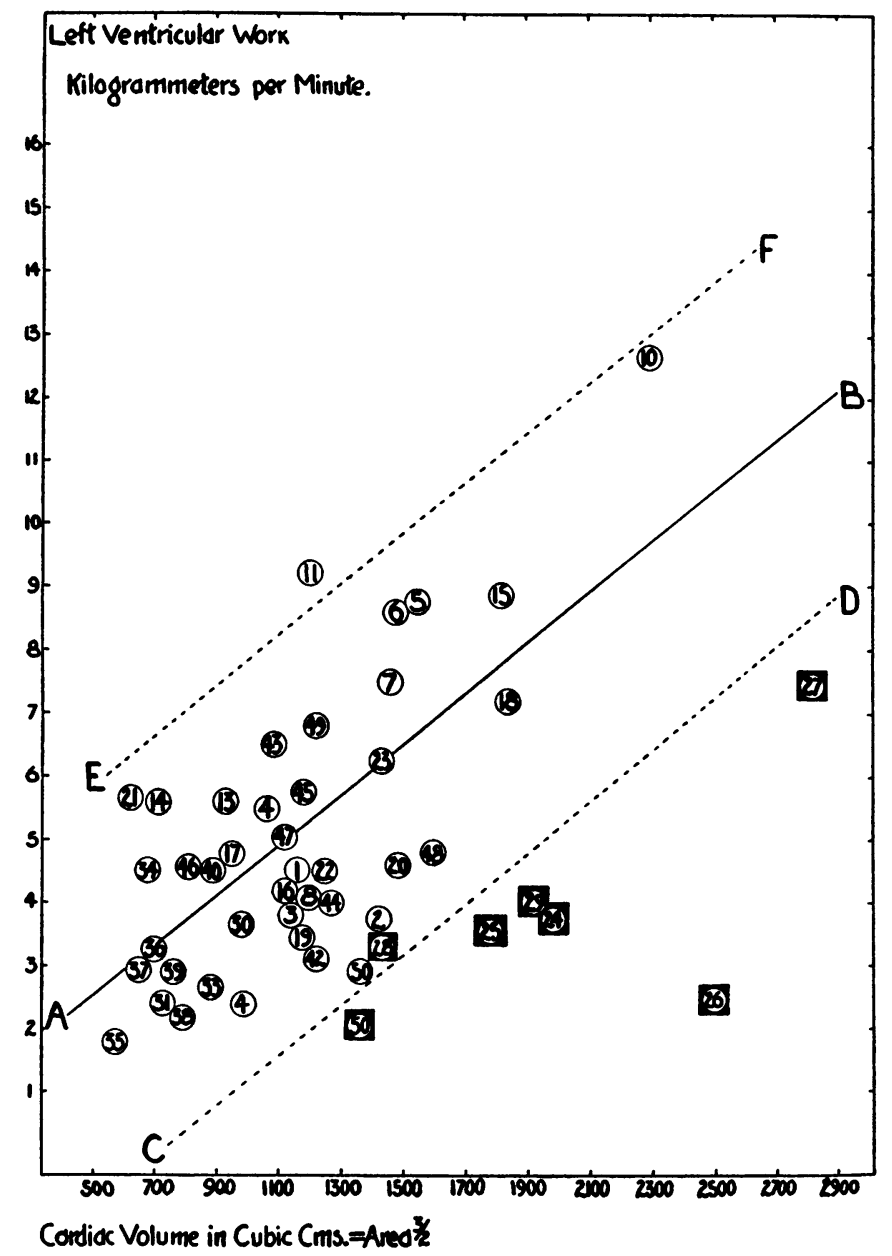

Fig. 3. Left Ventricular Work per Minute and Cardiac Volume

The values charted are the average of duplicate estimations. The unsatisfactory results on three cases have been omitted. Lines and symbols as in Fig. 1.

gives the correlation coefficients which pertain to the more interesting relationships.

A more detailed account of the results and their significance will be postponed until the general discussion of the problems before us. 


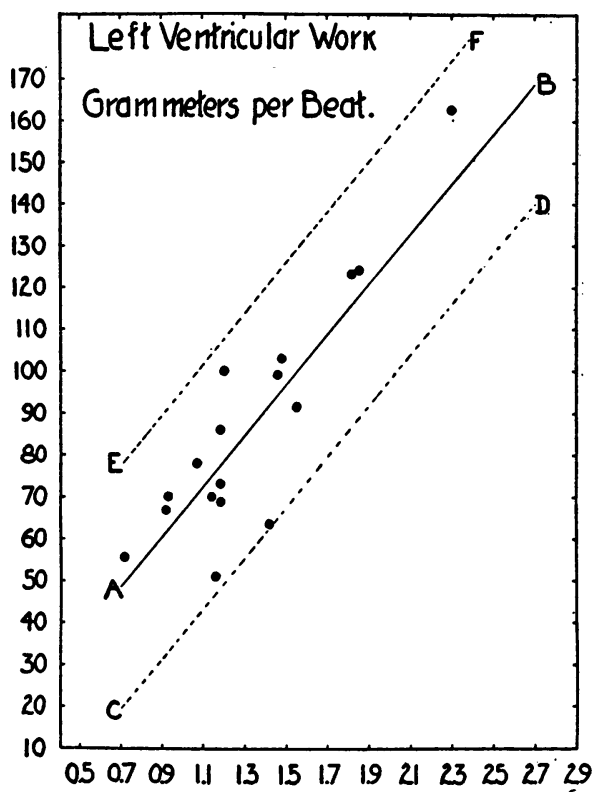

Volume of Heart in Liters $=$ (Areo in Square $\mathrm{Cms}$ ) 3 :

Fig. 4. Left Ventricular Work per Beat and Cardiac Volume in 17 Cases of Hypertension (Group II)

The lines pertain to the values charted.

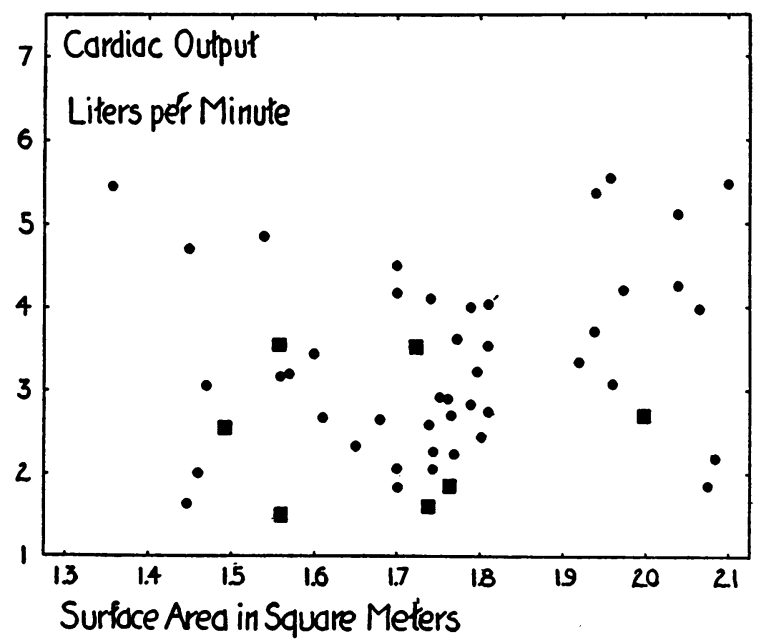

Fig. 5. Cardiac Output per Minute and Body Surface Area

Symbols as in Fig. 1. No cases have been omitted. The values charted are the average of duplicate estimations. 


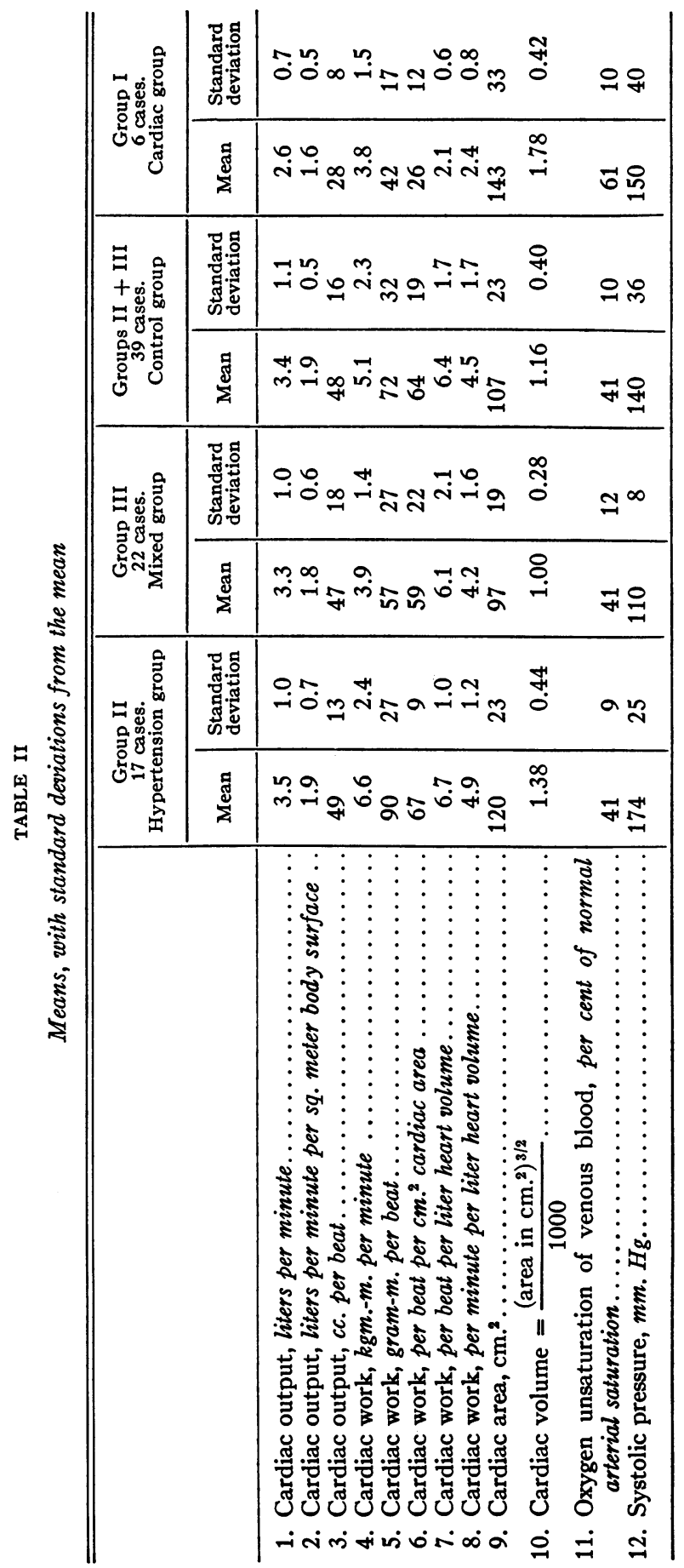


TABLE III

Correlation coefficients

\begin{tabular}{|c|c|c|c|}
\hline & $\begin{array}{c}\text { Group II } \\
\text { 17 cases. } \\
\text { Hypertension } \\
\text { group }\end{array}$ & $\begin{array}{l}\text { Group III } \\
\text { 22 cases. } \\
\text { Mixed } \\
\text { group }\end{array}$ & $\begin{array}{l}\text { Groups II + III } \\
39 \text { cases. } \\
\text { Control } \\
\text { group }\end{array}$ \\
\hline 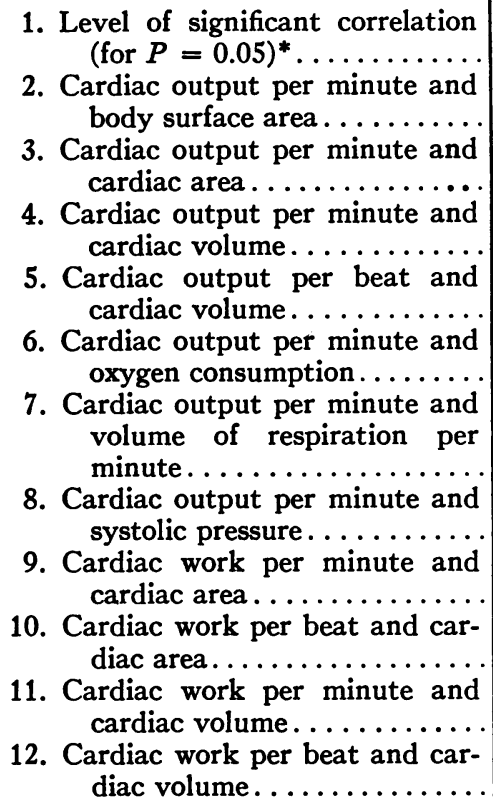 & $\begin{array}{l}0.34 \\
0.64 \\
0.85 \\
0.73\end{array}$ & $\begin{array}{l}0.57 \\
0.34 \\
0.53\end{array}$ & $\begin{array}{l}0.65 \\
0.31 \\
0.29 \\
0.69 \\
0.77\end{array}$ \\
\hline
\end{tabular}

* Since the level of significant correlation varies with the number of cases we have accepted the approximations to significant levels given by Fisher (31), Table 5A.

\section{Discussion}

The work of the heart and its relationships

Starling's "Law of the Heart" and its extension to clinical conditions. The direct relationship between heart size and heart work, in conditions in which the heart was functioning well, was demonstrated by Starling in experiments on the heart-lung preparation. The principle is summarized in his Linacre Lecture (32) on the "Law of the Heart." There he speaks of the work of the heart as a function of its volume; later, as a function of the active surface of the muscle fibres, and again, as a function of the length of the muscle fibres. In a later paper (18) a figure (number 5) shows that the relationship between diastolic ventricular volume and work per hour is linear. This has also been shown to be true of work per beat (15).

Our findings are in complete accord with this hypothesis. Figures 2 and 3 show that a similar relationship exists in the control group between 
the work of the left ventricle per beat and per minute and the cardiac volume. The correlation coefficients are 0.76 and 0.69 (Table III, items $12,11)$. By assuming the pulmonary pressure to be one-sixth of the aortic pressure the relationship of the total cardiac work to the volume of the heart can be calculated but the correlation coefficients would not differ significantly from those given above. Therefore we regard these high correlations as a demonstration that Starling's "Law of the Heart" may be extended to clinical conditions.

Considerations involved in the employment of Starling's law to detect cardiac disease. The results recorded in Figures 1, 2 and 3 show that in the clinic as in the heart-lung preparation the normal relationship does not hold for hearts which are threatened with failure. This suggests that we have a means of detecting the hearts so threatened. To attempt this it would be necessary to define the normal relationship between heart size and heart work, and especially to determine its limits, so that one could tell whether the results of a given case fall within or without the normal [or abnormal] group.

Which of the relationships between the various aspects of heart size and heart work would be best for this purpose cannot be finally determined. Those illustrated in Figures 1 and 2, heart area and heart volume against left ventricular work per beat, seem most promising. In each of these the control group has a high correlation coefficient, 0.77 and 0.76 respectively (Table III, 10,12). The lines representing twice the standard deviation include our values for the control group and exclude those for the cardiac group in both instances. In favor of the latter relationship is the expectation that the volume of the heart would be more closely related to the mass of cardiac muscle, and therefore a better function for comparison with the heart's work, than the silhouette area. But any estimate of the volume of the heart from the three halves power of the area involves an assumption which is not always valid, for the anteroposterior diameter of the heart is known to vary independently of the silhouette area in some instances. By using the area this assumption is avoided. On the other hand when the relationship between heart work and area is studied it is found that the control group has lost its unity. The cases of hypertension form a group_distinct from the remainder; the slopes of the respective regression lines are significantly different. When the cardiac work is plotted against the heart volume there is no such difference, so this relationship is to be preferred.

The mathematical definition of the normal heart size-work relationship and the detection of abnormality by means of $i t$. The question of the normality of a given case could be answered by finding the position on Figures 1, 2, 3 or 4 of the point obtained by plotting the results, and determining whether it fell within or without the normal area bounded by the dotted lines $C D$ and $E F$. The same answer could also be obtained 
by calculation from the equations of the regression lines, the normal limits being given by twice the standard deviation. A third method might be found simpler by persons not accustomed to mathematical calculations. The lower limit of normality may be given by the equations for the lower limiting lines $(C D)$. For example:

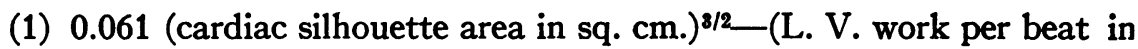
gm. meters) $=42$.

Simplifying the following equation by rounding out the slope from 1.06 to 1.00 ,

(2) (cardiac silhouette area in sq. cm.)-(L. V. work per beat in $\mathrm{gm}$. meters) $=78$.

Thus if the values found in a given case are inserted in either of these equations and the result is greater than the figure given the probability is about $\mathbf{9 7 . 5}$ in 100 that the case is abnormal with respect to myocardial function.

The limitations of this means of detecting cardiac abnormality. This definition of the normal relationship between heart work and size on the basis of a group of diverse cases, united only by the absence of congestive failure, must not be considered as final. Our results provide evidence that in one group, the cases of hypertension, it would be possible to apply more rigid criteria. Figure 4 shows the relationship between work per beat and volume in the seventeen cases of this group. The correlation is extraordinarily good, the coefficient being 0.85 (Table III, 10). The standard deviation about the regression line is so small that the limits of normality can be more closely defined than in the entire control group. Therefore, a slight diminution in the heart work-size ratio would place a case of hypertension outside the normal zone. These results suggest that the statistics of other groups of cases, i.e. thyrotoxicosis, rheumatic heart disease, etc., might allow a more rigid definition of the normal and so permit detection of myocardial abnormality earlier in the course of disease. This question cannot be answered till more data have been secured.

On the other hand it is not to be expected that the relationship of basal cardiac work and size would permit detection of all types of cardiac abnormality, even if the methods should be greatly improved. The result obtained in one case of angina pectoris (number 31) who later died of coronary thrombosis, is near the center of the normal range. Another case of this disease (number 2) also gave results within the normal limits. Those obtained on the third (number 30) are likewise normal, but the estimation was unsatisfactory because the patient hyperventilated. So we find that the condition of the heart in these patients is different from that of the cases threatened with decompensation. This finding is consistent with the diverse clinical courses of these two types of cardiac disease. 


\section{The cardiac output and its relationships}

To consider the relationships involving the heart's work is to concentrate attention on the condition of that organ. But the cardiac output is of importance to the rest of the body, because the blood supply of tissues other than the heart (19) depends on its magnitude. Therefore, in relation to metabolism and body size cardiac output is of chief interest; but in relation to heart size the output is of less interest than is the heart's work.

Cardiac output and cardiac size. In the control group the cardiac output is significantly related to the size of the heart, but the correlation is not as good as in the corresponding work relationships, except in the hypertensive group (Table III, 3 to 5, 9 to 12). This scattering of normal results interferes with the detection of cardiac abnormality by this relationship.

Cardiac output and body surface area. Our estimates of the cardiac output per minute per square meter of body surface, the usual method of reporting results, are shown on Figure 5. There is complete lack of correlation among the cases of hypertension. The mixed group shows a correlation which is just significant. A factor in this lack of relationship may be the close correlation between cardiac output and metabolism in both Groups II and III. When the metabolism deviates from the expected basal level in disease a corresponding change in cardiac output usually takes place, so that the normal relationship of cardiac output to body surface is lost.

The average cardiac output per minute, and this value per square meter of body surface (Table II, 1, 2) are both lower in the cardiac than in the control group but we have not yet obtained sufficient evidence to determine whether the difference is significant. Certain patients with advanced myocardial disease have larger cardiac outputs than some normal persons. Therefore, these values throw little light on the condition of the heart.

Cardiac output and oxygen consumption. Of more interest is the relationship between cardiac output and oxygen consumption, stressed by previous investigators as a result of studies on normal persons at exercise (20) and at rest (7). In our control group the correlation is good, the coefficient being 0.65 (Table III, 6 ); when Groups II and III are considered separately it is even better. From this relationship the arteriovenous oxygen difference can be calculated. In the cardiac group the amount of the arterial oxygen taken up by the tissues is 61 per cent, or 11 volumes per cent, in comparison with 41 per cent or 7.6 volumes per cent in the control group. Therefore the oxygen tension of the tissues in our cardiac cases must be lower than in normal persons. Analysis of arterial and peripheral venous blood has also demonstrated the increased arteriovenous oxygen difference in cardiac disease (21). Lack of oxygen being a 
cause of increased permeability (22) this may well be a factor in the production of edema in such cases.

Our value for the arteriovenous oxygen difference in the control group is somewhat larger than that obtained by certain other investigators. However, our mean value for eight normal young adults, 6 volumes per cent, agrees with that found by Grollman in similar subjects (7) using the acetylene cardiac output method, while that of the whole control group is very similar to the values found by Prodger and Dennig (23) using the same method. The smaller arteriovenous differences found in patients by cardiac puncture (24), (25), are probably not comparable with results obtained in the basal state for the patients were doubtless excited by this procedure. The differences between our results and those obtained in experiments in which the oxygen tension of mixed venous blood was calculated from rebreathed gas mixtures presumed to be in equilibrium with it (26), may be due to the fact that the slope of the oxyhemoglobin dissociation curve is so steep at this point, that a slight error would make a large difference in the calculated result.

\section{Data bearing on certain clinical conditions}

Hypertension. The results obtained on the seventeen cases of hypertension deserve special consideration. They disclose that the cases with small hearts have a smaller basal cardiac output than those with large hearts. In some cases the output per minute is smaller than in many normal persons, as has been demonstrated by others $(24,27)$. This reduced cardiac output permits the maintenance of hypertension without an increase in the heart's basal work. When the basal cardiac work is not elevated, the heart is not enlarged. When it is elevated, the amount of enlargement is closely proportional to the increased work. Therefore, our findings are consistent with the well known conception that cardiac hypertrophy is analogous to that which occurs in skeletal muscles after increased work.

The failure of three of our cases of prolonged hypertension (numbers 4 , 14, and 16) to develop evidence of cardiac hypertrophy may be attributed to the reduced cardiac output, an adaptation which spares the heart, though perhaps at the expense of other tissues. This furnishes a possible explanation for those cases of hypertension who show no cardiac hypertrophy at necropsy, (28). This explanation is consistent with the well known fact that cardiac failure is less likely to occur in cases of hypertension with small than with large hearts.

In striking contrast to the close correlation between heart work and heart size in our cases of hypertension, is the complete lack of relationship between cardiac output and body surface area in these cases (Table III, 9 to 12 and 2). 
In cases of hypertension the heart conforms to Starling's Law much more closely than is the case in normal individuals. This suggests that, when the heart is under strain, the basal cardiac work is determined chiefly by the mass of muscle. But when cardiac reserve is unimpaired, the basal cardiac work is more influenced by extracardiac factors.

Functional heart disease, hyperthyroidism, anemia, and paroxysmal tachycardia. In the other clinical classes the number of cases is too small to permit any generalizations, but certain of the results deserve comment. The four cases of functional heart disease are characterized by a low average cardiac output, both absolutely and per square meter of body surface. In this they resembled the cardiac group with which they have so many symptoms in common. Their arteriovenous oxygen difference, 50 per cent or 9.2 volumes per cent, was midway between the control and cardiac groups. The relationship between basal heart work and size was not abnormal because they had smaller hearts than normal.

Two of the three cases of hyperthyroidism had a slightly increased cardiac output per square meter of body surface, even though they were taking iodine. This feature of hyperthyroidism was first demonstrated by Liljestrand and Stenstrom (29).

The two cases of anemia did not show the increased cardiac output which we expected. Both of them appear to have reduced their basal metabolism to a point where a normal cardiac output will carry the necessary oxygen. In one of these patients starvation may well have been the cause of this decrease. This method of compensating for anemia is not that usually described.

The one case of paroxysmal tachycardia showed far less cardiac work per beat during the attack than afterward, a finding similar to that of Barcroft, Bock and Roughton (30). Unfortunately, no orthodiagram could be made during the attack; the patient could not stand. In charting the results it has been assumed that the size was unaltered. This decrease in work during the attack is perhaps analogous to the decrease of cardiac efficiency which occurs in the heart-lung preparation when the rate is increased (18).

\section{Summary}

(1) Duplicate determinations of cardiac output and metabolism, repeated estimations of blood pressure and pulse rate, and orthodiagrams have been assembled in fifty individuals. These estimations were performed on fasting subjects lying at rest, after a prolonged rest period. Those tested included apparently normal persons, patients who had recovered from congestive failure, and patients with some circulatory abnormality but not immediately threatened with failure, viz. thyrotoxicosis, hypertension, anemia, angina pectoris, compensated valvular disease and functional heart disease. 
(2) When the basal work of the left heart of these subjects is plotted against the volume of the heart or the area of the cardiac silhouette the points representing cases not threatened with failure are found to be arranged about a straight line. On the other hand the points representing cases threatened with failure are outside the limits of the normal cases.

(3) We regard our results as evidence that Starling's "Law of the Heart" holds for the basal cardiac work in diverse clinical conditions as well as for the heart lung preparation. Paraphrasing his words we may say, "Within physiological limits the larger the size of the heart, the greater is the energy of its contraction." And as a corollary, when the work of any heart is not commensurate with its size, that heart is threatened with failure.

(4) On the basis of a diverse group of cases believed to have normal myocardia we have made a preliminary estimate of the normal relationship between heart work and size. Charts and equations are submitted, by which the question of the normality of any case may be decided.

(5) The relationship between heart size and heart work per beat was especially striking in 17 cases of hypertension. Those with hearts of normal size, by reducing cardiac output, maintained their hypertension without greater expenditure of cardiac work than normal persons. The cases with large hearts were performing increased work. Considering increased cardiac work as cause of hypertrophy in the latter group, its absence will explain the absence of hypertrophy in the former.

(6) The cardiac output was directly related to the metabolism in the cases not threatened with failure. The arteriovenous oxygen difference was much smaller in these cases than in those who had been decompensated. The cardiac output was related to the size of the heart, but, as a rule, not so closely as was the cardiac work. There was a surprising lack of correlation between cardiac output and body surface area in cases of hypertension; the remainder of our control cases showed correlation above the level of significance.

(7) Although the errors in estimating basal cardiac output or work are undoubtedly large, the differences found in clinical conditions are so much larger that the results, properly interpreted, have clinical significance. 


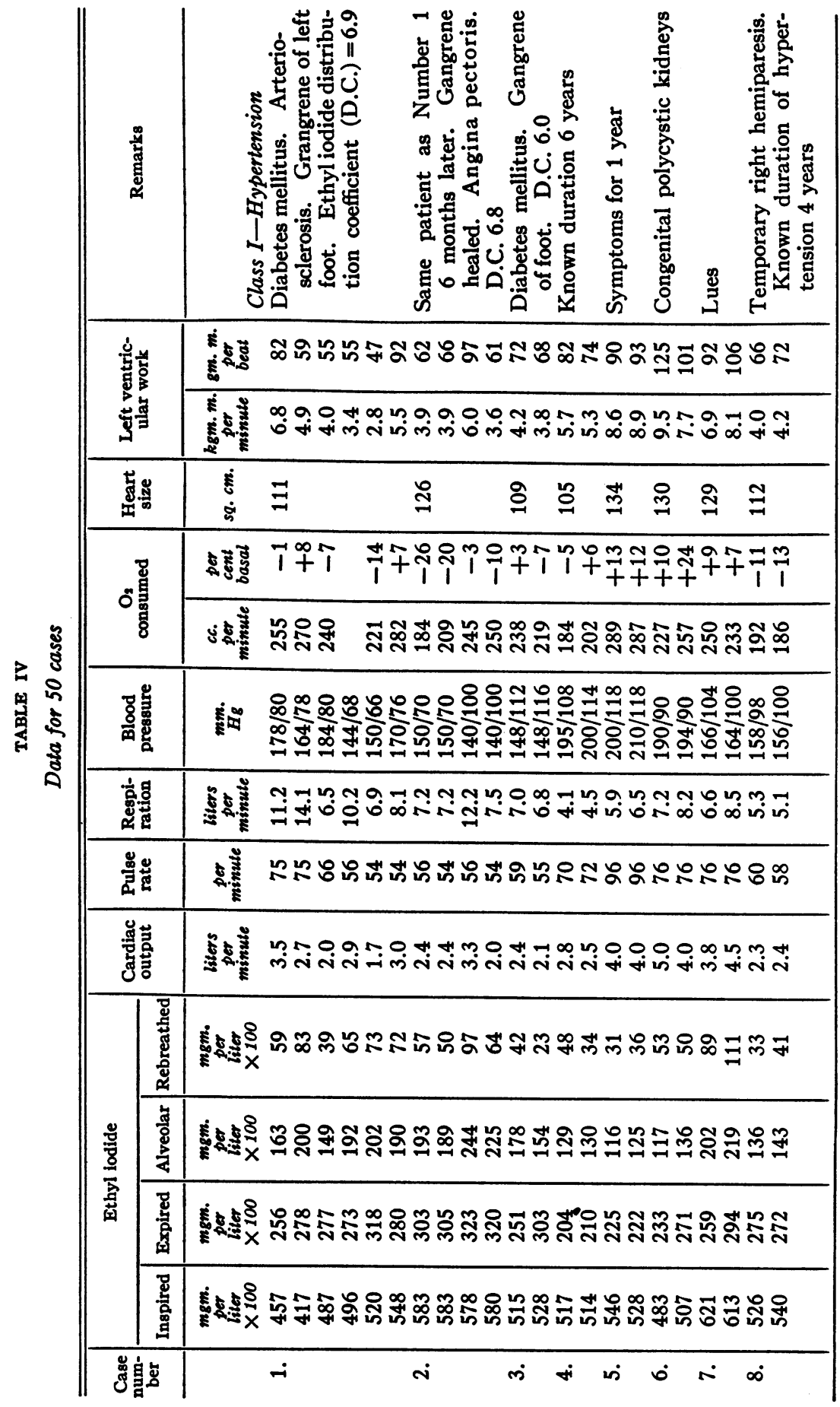


ISAAC STARR, JR., L. H. COLLINS, JR., AND F. C. WOOD

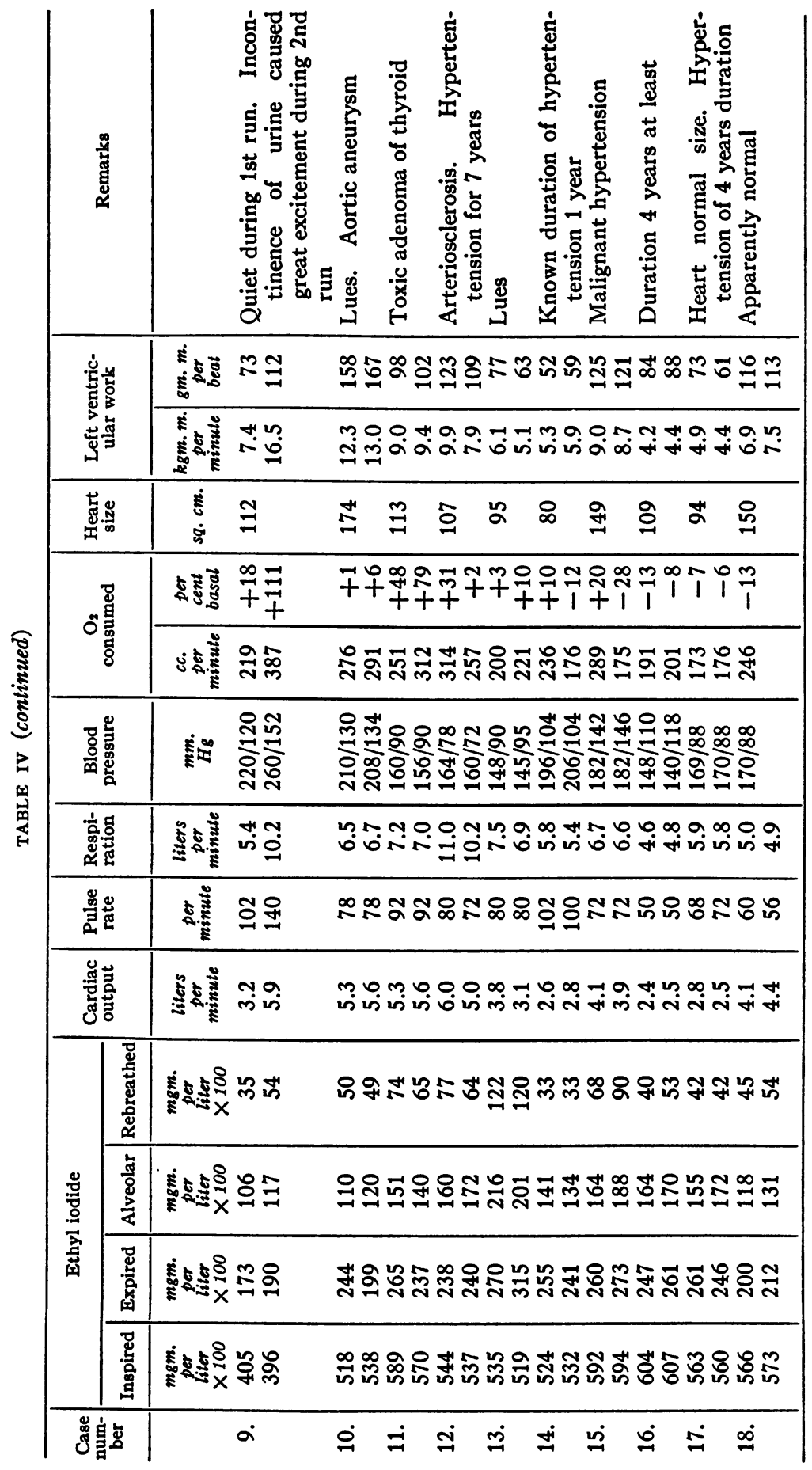




\begin{tabular}{|c|c|c|c|c|c|c|c|}
\hline & & 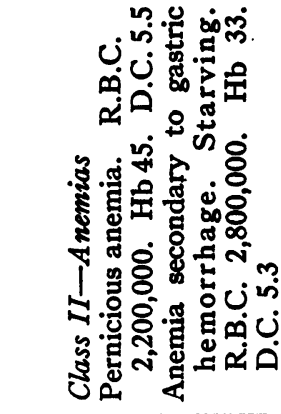 & 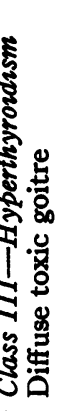 & 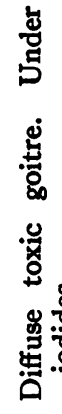 & 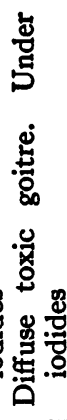 & हैं & 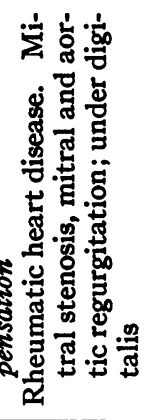 \\
\hline & & 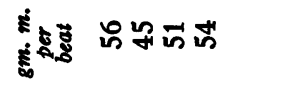 & & ơ & F⿻⺀ & & बे अ \\
\hline 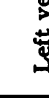 & & 题 & & ỹy & ใบบ & & $\ddot{m}$ \\
\hline$\frac{5}{d x}$ & & 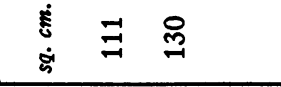 & 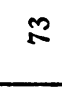 & $\stackrel{\circ}{=}$ & 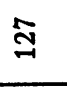 & & $\stackrel{\infty}{\sim}$ \\
\hline \multirow{2}{*}{ o } & \multirow{2}{*}{ 熝 } & 혀ㅇㅛㅛ & & 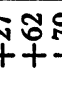 & $\begin{array}{l}\infty \\
0 \\
+\infty\end{array}$ & & $\underset{ก}{+}$ \\
\hline & & 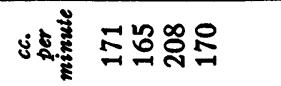 & & ثै & 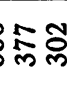 & & ్ํㅇํㅠ \\
\hline \multicolumn{2}{|c|}{ 诺 } & 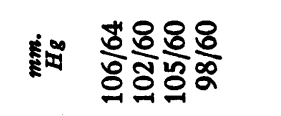 & & 萬 & 胥造 & & 윯요 족 \\
\hline \multicolumn{2}{|c|}{ 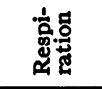 } & 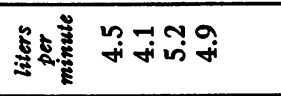 & & 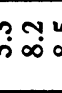 & ; & & $\dot{i}$ \\
\hline \multicolumn{2}{|c|}{ 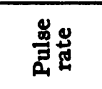 } & 蛋 & \multicolumn{4}{|c|}{ 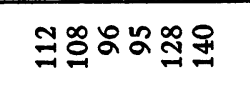 } & สูล \\
\hline \multicolumn{2}{|c|}{ 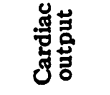 } & 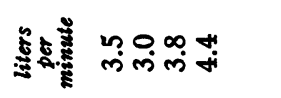 & \multicolumn{4}{|c|}{ 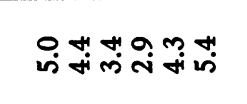 } & $\ddot{n} \dot{\infty}$ \\
\hline \multirow{4}{*}{ 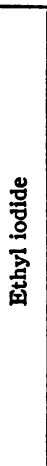 } & 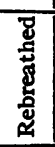 & 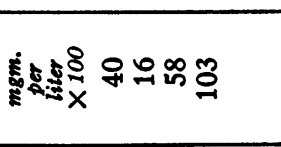 & \multicolumn{4}{|c|}{ q 守 } & 8 \\
\hline & $\begin{array}{l}\frac{5}{8} \\
\frac{8}{8}\end{array}$ & 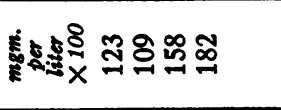 & \multicolumn{4}{|c|}{ 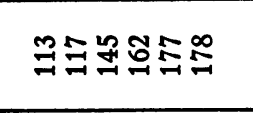 } & $\stackrel{\alpha}{\circ} \stackrel{0}{0} \stackrel{0}{\circ}$ \\
\hline & 葛 & 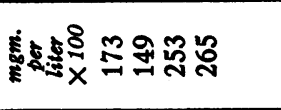 & \multicolumn{4}{|c|}{ 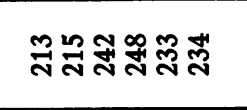 } & 夛 \\
\hline & 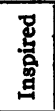 & 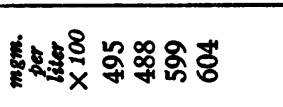 & \multicolumn{4}{|c|}{ 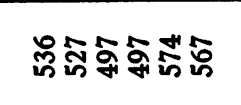 } & శ్రి \\
\hline \multicolumn{2}{|c|}{ 兽臬 } & $\dot{2} \dot{8}$ & $\dot{\mathrm{N}}$ & ส่ & $\ddot{\sim}$ & & ম் \\
\hline
\end{tabular}


ISAAC STARR, JR., L. H. COLLINS, JR., AND F. C. WOOD

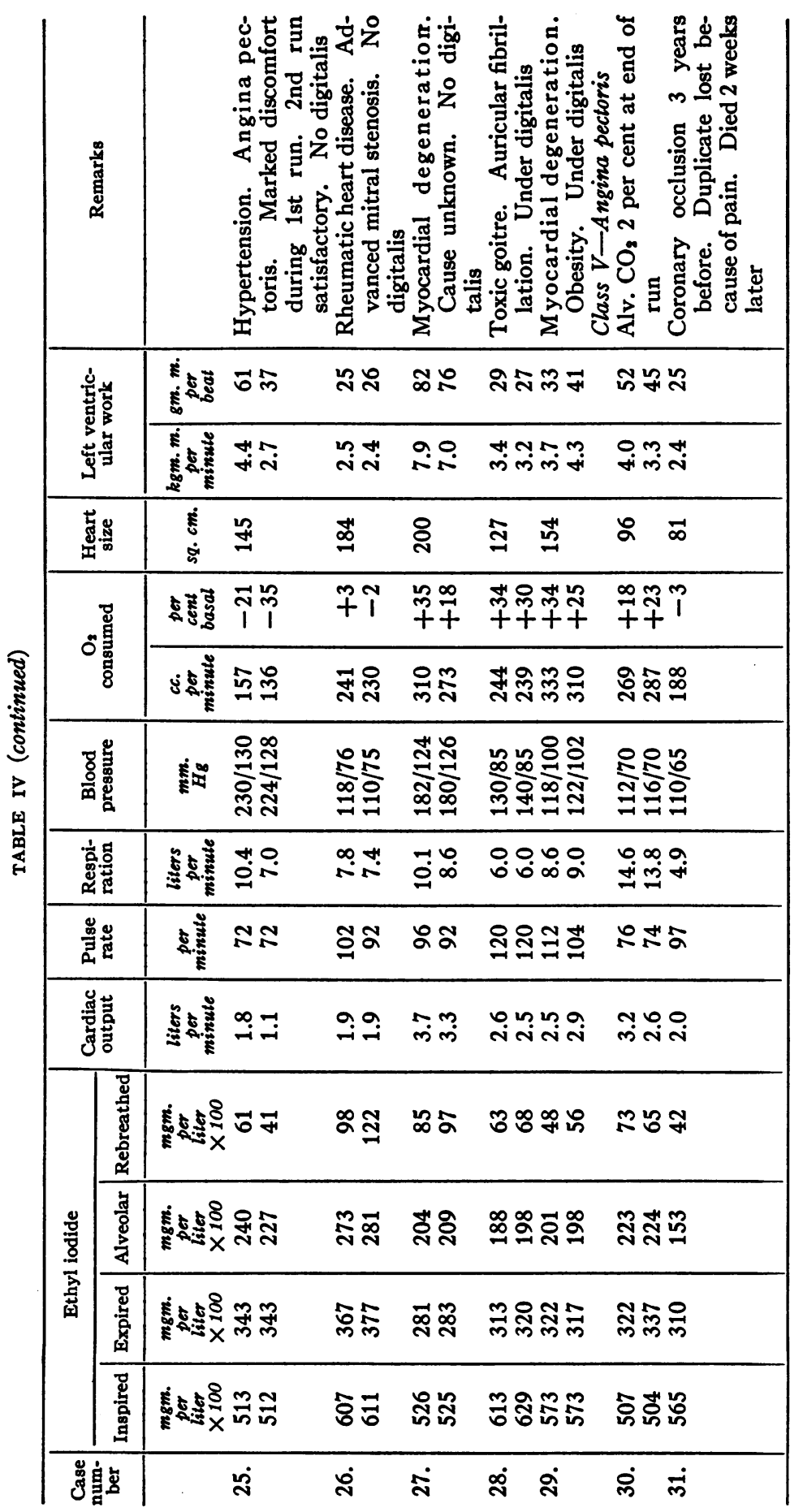




\begin{tabular}{|c|c|c|c|c|}
\hline & & 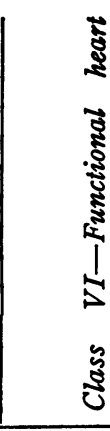 & 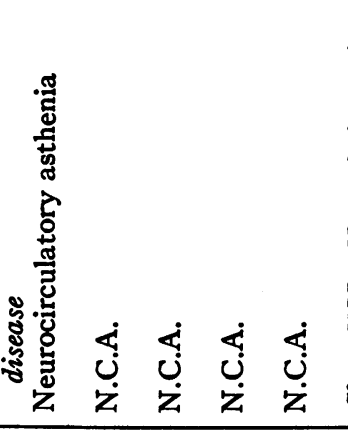 & 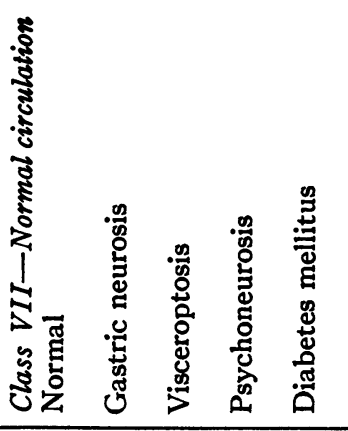 \\
\hline$\dot{\mathrm{E}}$ & & s: & 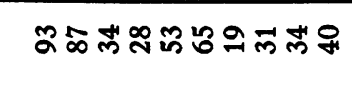 & 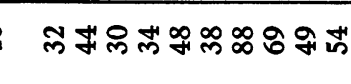 \\
\hline 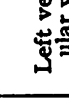 & & s: & 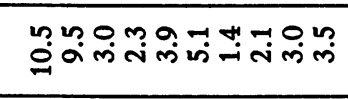 & 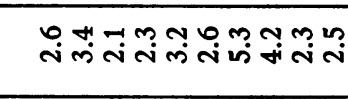 \\
\hline 丵: & & $\begin{array}{l}\dot{5} \\
\dot{\mathrm{s}} \\
\end{array}$ & $\kappa$ 요 8 & Кト⿱ $\infty \infty_{\infty} \Omega$ \\
\hline & & Ez & 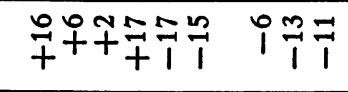 & 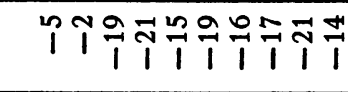 \\
\hline & & 35 & 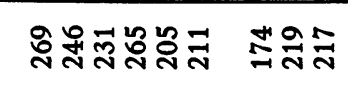 & 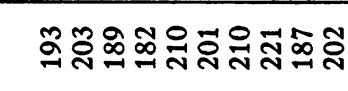 \\
\hline$\frac{8}{m}$ & & iั & 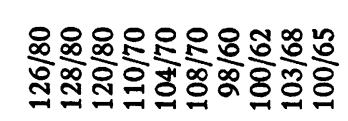 & 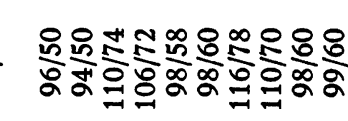 \\
\hline 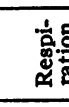 & & Etg & 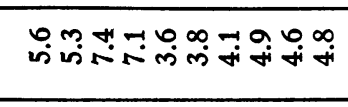 & 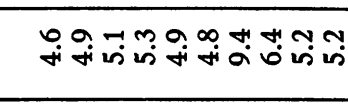 \\
\hline 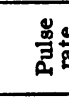 & & 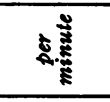 & 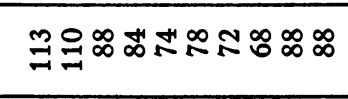 & 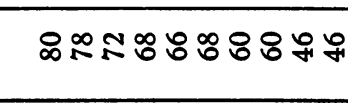 \\
\hline 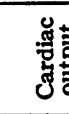 & & 8 & 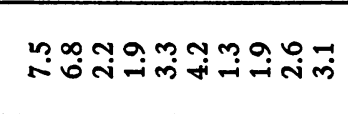 & 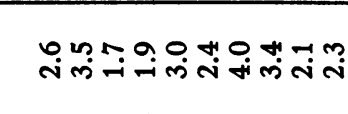 \\
\hline \multirow{4}{*}{ 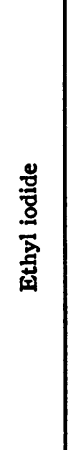 } & 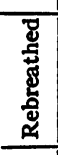 & हt: & 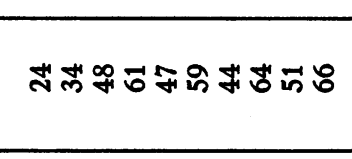 & 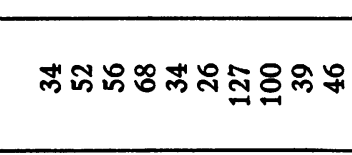 \\
\hline & $\begin{array}{l} \\
\frac{5}{0} \\
\frac{8}{4} \\
\end{array}$ & tits & 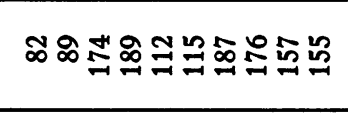 & ్ㅜ \\
\hline & 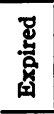 & 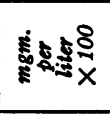 & 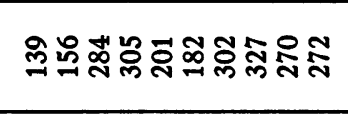 & 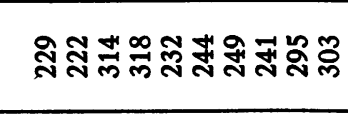 \\
\hline & $\begin{array}{l}\bar{\Xi} \\
\text { 兽 } \\
\end{array}$ & 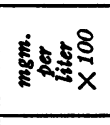 & 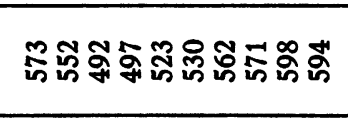 & 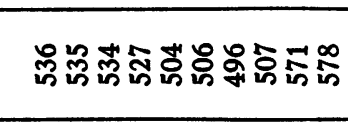 \\
\hline \multicolumn{2}{|c|}{ 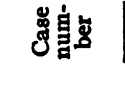 } & & 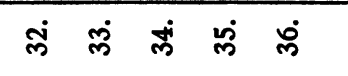 & 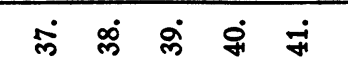 \\
\hline
\end{tabular}


ISAAC STARR, JR., L. H. COLLINS, JR., AND F. C. WOOD

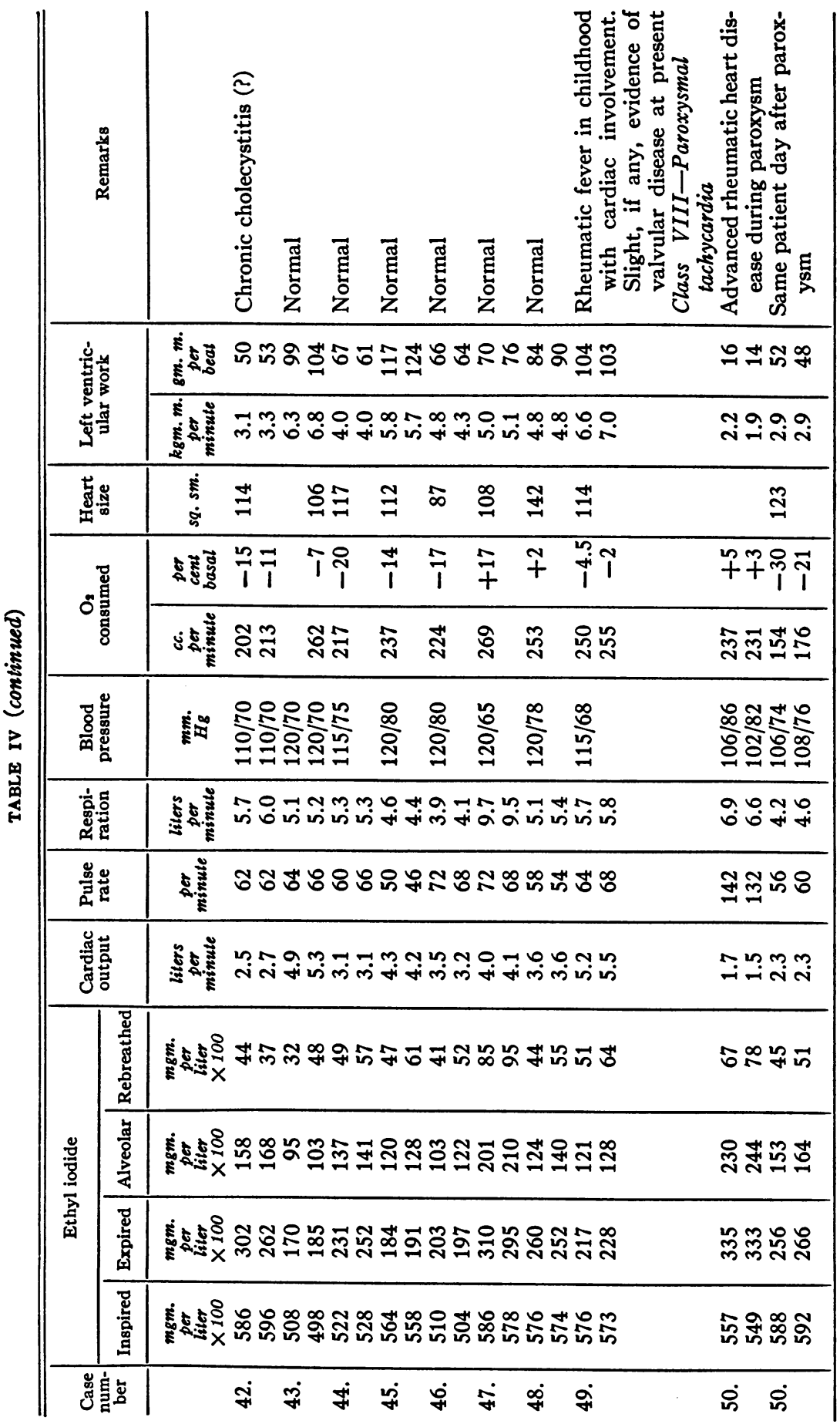




\section{BIBLIOGRAPHY}

1. Henderson, Y., and Haggard, H. W., Am. J. Physiol., 1925, lxxiii, 193. The Circulation and its Measurement.

2. Starr, I., Jr., and Gamble, C. J., J. Biol. Chem., 1927, 1xxi, 509. A Method for the Determination of Minute Amounts of Ethyl Iodide in Air, Water, and Blood by means of its Reaction with Silver Nitrate; and Experiments Bearing on the Determination of Blood Flow by means of Ethyl Iodide.

3. Starr, I., Jr., and Gamble, C. J., Am. J. Physiol., 1928, lxxxvii, 474. The Behavior of Ethyl Iodide in the Body.

4. Starr, I., Jr., and Gamble, C. J., Am. J. Physiol., 1928, lxxxvii, 450. An Improved Method for the Determination of Cardiac Output in Man by means of Ethyl Iodide.

5. Henderson, Y., J. A. M. A., 1931, xcvii, 1265. The Volume of the Circulation and its Regulation by the Venopressor Mechanism.

6. Starr, I., Jr., and Collins, L. H., Jr., Am. J. Physiol., 1931. xcvi, 228. Studies of Cardiac Output in Normal Men.

7. Grollman, A., Am. J. Physiol., 1929, xc, 210. Physiological Variations in the Cardiac Output of Man. VI. The Value of the Cardiac Output of the Normal Individual in the Basal, Resting Condition.

8. Lauter, S., Münch med. Wchschr., 1930, lxxvii, 526. Kreislaufprobleme. Münch. med. Wchschr., 1930, lxxvii, 593. Kreislaufprobleme.

9. Eyster, J. A. E., J. A. M. A., 1931, xcvii, 1268. Discussion of Henderson (5).

10. Heckscher, H., Arch. f. d. ges. Physiol., 1930, ccxxvi, 431. Untersuchungen über das Sauerstoffdefizit und die Kohlensäurespannung in der Alveolarluft.

11. Starling, E. H., Principles of Human Physiology. Lea and Febiger, Philadelphia, 1930, 5th ed. p. 734.

12. Bazett, H. C., Heart, 1920, vii, 353. An Analysis of the Time-Relations of Electrocardiograms.

13. Starling, E. H., Reference 11, p. 735.

14. Frank, O., Ztschr. f. Biol., 1899, xxxvii, 511. Die Grundform des arteriellen Pulses. E. Bie Berechnung der Herzarbeit.

15. Katz, L. N., Am. J. Physiol., 1932, xcix, 579. Observations on the External Work of the Isolated Turtle Heart.

16. Bardeen, C. R., Am. J. Anat., 1918, xxiii, 423. Determination of the Size of the Heart by Means of the X-Rays.

17. Fühner, H., and Starling, E. H., J. Physiol., 1913, xlvii, 286. Experiments on the Pulmonary Circulation.

18. Starling, E. H., and Visscher, M. B., J. Physiol., 1926, 1xii, 243. The Regulation of the Energy Output of the Heart.

19. Anrep, G. V., Physiol. Rev., 1926, vi, 596. The Regulation of the Coronary Circulation.

20. Christensen, E. H., Arbeitsphysiol., 1931, iv, 470. V. Mitteilung: Minutenvolumen und Schlagvolumen des Herzens während schwerer körperlicher Arbeit.

21. Barach, A. L., and Woodwell, M. N., Arch. Int. Med., 1921, xxviii, 367. Studies in Oxygen Therapy with Determinations of the Blood Gases. I. In Cardiac Insufficiency and Related Conditions.

22. Landis, E. M., Am. J. Physiol., 1928, lxxxiii, 528. Micro-injection Studies of Capillary Permeability III. The Effect of Lack of Oxygen on the Permeability of the Capillary Wall to Fluid and to the Plasma Proteins. 
23. Prodger, S. H., and Dennig, H., J. Clin. Invest., 1932, xi, 789. A Study of the Circulation in Obesity.

24. Lauter, S., Verhandl. d. deustch. Gesellsch. f. Kreislaufforsch., 1930-1931, iii-iv, 23. Weitere untersuchungen über den Kreislauf bei Hochdruck.

25. Baumann, H., and Grollmann, A., Ztschr. f. klin. Med., 1930, cxv, 41. Über die theoretischen und praktischen Grundlagen und die klinische Zuverlässigkeit der Acetylenmethode zur Bestimmung des Minutenvolumens.

.26. Peters, J. P., and Van Slyke, D. D., Quantitative Clinical Chemistry, Volume II. Methods. Williams and Wilkins Co., Baltimore, 1932, p. 161.

27. Ewig, W., and Hinsberg, K., Ztschr. f. klin. Med., 1930, cxv, 693. Kreislaufstudien. II.

28. Bell, E. T., and Clawson, B. J., Arch. Path., 1928, v, 939. Primary (Essential) Hypertension.

29. Liljestrand, G., and Stenstrom, N., Acta med. Scandinav., 1925, lxiii, 99. Clinical Studies on the Work of the Heart during Rest.

30. Barcroft, J., Bock, A. V., and Roughton, F. J., Heart, 1921, ix, 7. Observations on the Circulation and Respiration in a Case of Paroxysmal Tachycardia.

31. Fisher, R. A., Statistical Methods for Research Workers. Oliver and Boyd, Edinburgh 1930.

32. Starling, E. H., The Linacre Lecture on the Law of the Heart, 1918. Longmans, Green \& Co., London and New York.

33. Lindhard, J., Verhandl. d. deutsch. Gesellsch. f. Kreislaufforschung, 1930-31, iii, 85. Über die Verwendung der Kreislaufbestimmungen in der Klinik. 